\title{
ТРАНСФОРМАЦИЯ НОРМАТИВИЗМА: КАК АВТОМАТИЗАЦИЯ ПОВЛИЯЕТ НА РАЗВИТИЕ ТЕОРИИ ПРАВА
}

\author{
(c) 2020 Орлов Михаил Александрович \\ аспирант кафедры ТГиП Школы права Института права и управления \\ Московский городской педагогический университет, Россия, Москва \\ E-mail:mix190395@yandex.ru
}

Процессы поиска оптимальной концепции правопонимания в Российской Федерации сталкиваются с необходимостью адаптироваться под новые цифровые реалии. Автоматизация и цифровизация некоторых общественных процессов уже стала обыденностью. В связи с развитием данных процессов возникает вопрос об актуальности существующих подходов к правопониманию. Делается вывод о возможности цифровой модернизации современного Российского нормативизма.

Ключевые слова: нормативизм, интегративное правопонимание, конщепции правопонимания, информационный подход к правопониманию, автоматизация, цифровизация, машиночитаемое право.

В последние пять-десять лет в Российской юридической литературе обострились дискуссии относительно поиска новых парадигм права и подходов к правопониманию. Укрепились две точки зрения относительно оценки концепций правопонимания, которые возможно использовать применительно к процессам автоматизации и цифровизации. Первая состоит в признании юридического позитивизма (нормативизма) действующей и полноценной концепции правопонимания, не исключая возможности ее модернизации. Вторая же представляет собой интегративный подход к правопониманию, предполагающий объединение различных подходов в нескольких вариациях.

Истоки данной дискуссии лежат в необходимости переосмысления роли права в постсоветской действительности, повышения эффективности российской судебной системы, разрешения проблемы доминирования исполнительной власти в России. Нормативизм привнес в теорию права стройную систему, а также объяснил явление права на формальной позитивистской основе [1]. В то же время, нормативизм практически не вопринимает правовые сущности, для которых отсутствует четкое определение. Например, понятие «свободы» в широком истолковании может принимать значение «анархии» или «права сильного», что вряд ли согласуется с целями правового регулирования демократического государства. Соответственно, включение такого понятия в понятийный аппарат нормативизма должно сопровождаться как минимум его системной оценкой, что предпола- гает его узкое толкование.

Закостенелость нормативизма не могла оставить равнодушными исследователей права. Его жесткая иерархичность шла вразрез с появлением новых областей правового регулирования, применении цифровых технологий в правотворчестве и правоприменении, необходимости по-новому осмыслить структуру системы права, привнеси в нее новые элементы. Например, как отмечает Хабриева Т. Я., система права сталкивается с трансформацией в виде появления циклических правовых массивов, которые не могут быть встроены в существующую систему [2]. Например, Залоило М.В. и Черногор Н.Н. предлагают отнести к таким массивам совокупность правовых норм, разработанных в России в связи с распространением новой коронавирусной инфекции (COVID-19) [3].

Помимо внутрисистемных ограничений нормативизма существуют и иные, не происходящие из внутреннего строения системы. Так, признание высшей ценностью прав человека возможно в нормативизме только при условии соответствующего государственного санкционирования. Концепция естественных прав человека не может быть полностью включена в нормативизм, т.к. исключает государственное санкционирование как основной фактор наделения правовой нормы юридической силой.

Вопрос соотношения естественно-правовой и нормативистской концепции является особенно актуальным, в том числе и в период пандемии COVID-19. Как указывает Совет Европы, применение некоторых общепризнанных принципов 
права, в т.ч. стандартов соблюдения прав человека, может быть ограничено в необходимом объеме с целью сохранения «жизни нации» [4]. В условиях чрезвычайной ситуации необходимые четкие и слаженные действия государства и общества, что означает выработку конкретных правил поведения (норм права). Нормативизм в данном случае выступает как система, способная обеспечить функционирование таких правил. При этом механизмы демократического государства позволяют избежать злоупотребления нормами права, и их применение происходит согласно общепризнанным принципам, закрепленным в международных документах.

В попытках преодолеть названные ограничения нормативизма и иные его недостатки некоторыми исследователями разрабатывается интегративный подход к правопониманию. Следует указать, что данный подход не гомогенен, он имеет множество концепций по интеграции различных вариантов теорий права. При этом одни концепции могут частично противоречить другим. Например, под интеграцией могут понимать:

1. Объединение известных атрибутов существующих школ правопонимания;

2. Выявление общих точек соприкосновения различных типов правопонимания [5];

3. Объединение норм, отношений и правосознания, т.е. представлений о том, каким должны быть правовые нормы и правовые отношения [6];

4. Включение в правовую систему нормативных правовых актов, содержащих нормы права и иных форм права, прежде всего, основополагающих (фундаментальных) принципы права, нормативных правовых договоров, содержащих нормы права, а также обычаев, содержащих нормы права [7].

Как можно наблюдать, уже на этапе определения предмета интеграции возникают некоторые сложности. Предмет интеграции слишком абстрактен в одной трактовке и достаточно узок в другой. Проблемы возникают и в других сторонах данного подхода. Из неопределённого предмета интеграции следует отсутствие методики интеграции. Также отсутствует сколько-нибудь внятное описание системы права в интегративном правопонимании. В целом, данный подход даже спустя несколько десятков лет после появления первых публикаций остается недостаточно разработанным и буквально топчется на месте. Возможно, разработка данного подхода затянется на долгие годы. Однако интегративный подход, при всех его плюсах и минусах, все же пытается отойти от позитивистской догматики и использовать общие принципы права, закрепленные на международном уроне.

Нормативизм, в свою очередь, предоставляет достаточно четкое понимание системы права, ее соотношение с системой законодательства, объясняет понятие права, разделяет право на отрасли, подотрасли и более низкоуровневые структурные единицы, вплоть до нормы права. При этом нормативизм не исключает его дополнение другими структурами, институтами. Он имеет возможность адаптироваться под реалии времени, иметь для этого гносеологические обоснование, хотя для такого преобразования может потребоваться несколько лет.

Такие качества нормативизма могут помочь ему в дальнейшей трансформации ввиду стремительного технологического развития общества. Как отмечает Синюков В.Н., «делается всё более актуальной проблема системной правовой интерпретации происходящих социальных и технических изменений» [8]. Хотя решение данной проблемы видится Синюковым В.Н. в разработке нового цифрового социального регулятора вместо «устаревшего» права, это предложение достаточно дискуссионно. Например, не учитывается сохранение сущности правоотношений при их переносе в цифровое пространство. Появление же принципиально новых правоотношений, ради которых необходимо вводить новое «цифровое» право, приходится на достаточно отдаленную перспективу.

Существует и другой подход к нормативизму в российской юридической литературе, основанный на признании интегративного характера российского нормативизма [9]. Признается, в том числе, его ориентация на наблюдаемые в обществе отношения и явления, уже на основании которых нормативизм выстраивает систему правового регулирования. Участие граждан и общественных организаций в нормотворчестве и государственном управлении, закрепление естественных прав человека как неотчуждаемых не противоречат принципам нормативизма в демократических государствах. Однако это не является интеграцией в буквальном ее толковании. Авторами подтверждается наличие минимальных противоречий между выстроенной системой нормативизма и наблюдаемым фактам и 
явлениям жизни, указывается на адаптивность всей системы. Данный подход скорее укрепляет позиции нормативизма в научном сообществе, чем трансформирует его в иную концепцию.

Одним из направлений технологического развития общества является внедрение процессов автоматизации в различные сферы деятельности. Автоматизация преследует цель максимально эффективного использования какого-либо общественного или производственного процесса без непосредственного вмешательства человека. Возможно говорить об автоматизации процессов правотворчества и правоприменения в будущем, т.к. данные процессы по своей природе являются информационными процессами, в рамках которых правовая информация передается от одного участника правоотношений другому. Если рассматривать право с точки зрения информационной системы, то это открывает возможность для автоматизации процессов внутри системы. В таких условиях невозможно отрицать будущее влияние автоматизации на право.

Данная проблема стала активно разрабатываться в России с 2018 года, с утверждением Национальной программы «Цифровая экономика» в соответствии с Указом Президента России от 7 мая 2018 года № 204 «О национальных целях и стратегических задачах развития Российской Федерации на период до 2024 года». С точки зрения теории права представляет интерес раздел 6 паспорта национальной программы. Предполагается постепенное внедрение процессов автоматизации в правотворчестве и правоприменении, создание машиночитаемых норм права с помощью применения современных и перспективных информационных технологий, таких как искусственный интеллект, обработка больших данных, распределенные реестры и прочие.

Создание модели правового регулирования, основанной на машиночитаемом и автоматически применяемом праве, позволит решить несколько глобальных правовых проблем. Так, изза технологической необходимости построения четкой иерархической системы права в ее взаимосвязи с высокотехнологичными устройствами взаимодействия с такой системой, устранится необходимость толкования законодательства, а нарушить закон станет трудно из-за технической невозможности сделать это [10]. Вследствие этого, судебная система претерпит значительные изменения. В зависимости от уровня ма- шинизации и автоматизации права, судебная система может незначительно реформироваться, добавив возможность для самостоятельного принятия судебных актов программой по типовым делам, так и трансформироваться в сообество наиболее профессиональных юристов как системы совещательных органов, предоставив отправление правосудия полностью на откуп программам.

Данные изменения в том или ином масштабе затронут все процессы правоприменения, что приведет к сокращению штатной численности в государственных органах, общей оптимизации деятельности государственных органов за счет их реорганизации и распределения полномочий. Не будут исключением и процессы правотворчества, которые могут быть значительно оптимизированы за счет сбора «больших данных» об актуальных общественных запросах, автоматической проверки согласованности данного запроса с действующей системой права, принятия закона в качестве программного кода и т.д. Конечно, это всего лишь малая часть изменений, которые могут возникнуть при введении машиночитаемого и автоматически применяемого права. Для целей данной статьи необходимо общее представление о таких изменениях, однако критически важно обозначить общие направления развития для всей системы права.

Возникает вопрос - необходима ли внесение изменений в существующую теорию нормативизма в связи с ожидаемыми изменениями? Или наиболее подходящим может оказаться интегративное правопонимание? Думается, что современный российский нормативизм в целом соответствует целям и задачам, стоящим перед правом в будущем. В том числе, к таким задачам относится автоматизация правотворчества и правоприменения. Нормативизм не исключает применения к правотворчеству и правоприменению новых методов, пока они не изменяют саму сущность данных процессов.

Действующая система права претерпит незначительные изменения, т.к. все еще будет существовать необходимость в группировке норм права по отраслям и институтам ввиду различия принципов и предметов правового регулирования. Однако систему права, ее отдельные элементы и структуру следует рассматривать с точки зрения информационного подхода к правопониманию. Черданцев А.Ф. указывает, что информационное свойство права проявляется 
в правовом регулировании как «воздействие различных видов информации (прежде всего предписывающей) на сознание людей» и как «движение различного вида правовой информации, складывающейся из различных идеальных объектов, к числу которых относятся и принципы права» [11]. Применение информационного подхода к правопониманию, т.е. оценки права как информационной системы, позволит ускорить и оптимизировать внедрение процессов автоматизации. Система права в современной нормативистской трактовке позволяет применить к ней некоторые положения теории информации, в т.ч. о каналах связи. Автоматизация и цифровизация может быть применима максимально эффективно к праву и правовым нормам в контексте интерпретации данных понятий как информационных явлений или, если рассматривать их в узком смысле, программных кодов машиночитаемого права. Однако невозможно создать подобную программу для ЭВМ, написать программный код, если не имеется системное понимание происходящих в праве процессов.

Также существуют и технологические ограничения на создание машиночитаемого и автоматически применяемого права. Например, значительно затруднен перевод в цифровое пространство объекта без заданных параметров, т.е. общественных явлений без четкого определения понятия. Создание машиночитаемых норм права потребует перевода в программный код всех структурных элементов правовой нормы для каждого возможного правоотношения. С расширением машинизации и автоматизации в праве, все больше норм права будут приобретать казуистичный характер. При переводе нормы права в машиночитаемый формат возникает необходимости четкости и большей конкретизации норм права. Машиночитаемая норма права должна иметь конкретный предмет регулирования, во избежание конфликта с другими машиночитаемыми нормами. Таким образом, технологические ограничения разработки программного обеспечения (без которого невозможна автоматизация правоприменения и правотворчества) и необходимость системного понимания права делают нормативизм единственной концепцией правопонимания, способной адаптироваться к новой цифровой реальности. В то же время, отсутствие системного описания права в интегративном правопонимании делает затруднительным или даже невозможным изучение и применение в ней процессов автоматизации.

\section{Библиографический список}

1. Денисенко В.В., Сухинин А. Ю. Советский нормативизм как теоретико-правовая парадигма // Вестник РУДН. Серия: Юридические науки. 2017. № 3. URL: https://cyberleninka.ru/article/n/sovetskiy-normativizm-kakteoretiko-pravovaya-paradigma (дата обращения: 02.10.2020).

2. Хабриева Т. Я. Циклические нормативные массивы в праве // Журнал российского права. 2019. № 12. URL: https://cyberleninka.ru/article/n/tsiklicheskie-normativnye-massivy-v-prave (дата обращения: 02.10.2020).

3. Черногор Н.Н., Залоило М.В. Метаморфозы права и вызовы юридической науке в условиях пандемии коронавируса // Журнал российского права. 2020. № 7. С. 18

4. Соблюдение принципов демократии, верховенства права и прав человека в условиях эпидемиологического кризиса COVID-19. Руководство для государств - членов. URL: https://rm.coe.int/sg-inf-2020-11-toolkitfor-member-states-during-the-covid-19-sanitary-/16809e3992 (дата обращения: 31.10.2020)

5. Залоило М.В., Черкашина-Шмидт О.В.Интегративное правопонимание: новый подход // Журнал российского права. 2014. № 4 (208). URL: https://cyberleninka.ru/article/n/integrativnoe-pravoponimanie-novyypodhod (дата обращения: 07.10.2020).

6. Палеха Р. Р. Интегративная концепция правопонимания как методологическая парадигма права // Вестник Воронежского государственного университета.- Воронеж: Изд-во Воронеж. ун-та, 2010, № 1 (8). - С. 67

7. Ершов В.В. Теоретические и практические проблемы правопонимания, правотворчества и правоприменения // Российское правосудие. 2008. № 7. С. 14

8. Синюков В.Н.Цифровое право и проблемы этапной трансформации российской правовой системы // Lex Russica. 2019. № 9 (154). URL: https://cyberleninka.ru/article/n/tsifrovoe-pravo-i-problemy-etapnoitransformatsii-rossii-skoi-pravovoi-sistemy (дата обращения: 10.10.2020).

9. Скоробогатов А.В., Краснов А.В.Интегральный характер современного российского нормативизма // КHЖ. 2015. № 1 (10). URL: https://cyberleninka.ru/article/n/integralnyy-harakter-sovremennogo-rossiyskogonormativizma (дата обращения: 16.10.2020). 
10. Романов А.Ю.Проблемы перевода норм права в машиночитаемый вид и автоматизации их применения судом//Язык правотворчества в условиях цифровизации общественных отношений. Сборник научных трудов. ИНФРА-М. 2019. Москва. С.219

11. Черданцев А. Ф. Интегративное недопонимание права // Журнал российского права. 2016. № 10 (238). URL: https://cyberleninka.ru/article/n/integrativnoe-nedoponimanie-prava (дата обращения: 26.10.2020). 